\title{
Google Classroom: An Effective Virtual Platform to Teach Writing in an EFL Composition Course
}

\author{
Kevin Armando Brand Fonseca ${ }^{1} \&$ Federico Soto Peralta ${ }^{1, *}$ \\ ${ }^{1}$ English department, Universidad Nacional, Costa Rica \\ *Correspondence: English department, Universidad Nacional, Costa Rica. E-mail: federico.soto.peralta@una.cr
}

Received: November 28, 2018

Accepted: December 20, 2018 Online Published: January 20, 2019

doi:10.5430/ijelt.v6n1p27

URL: https://doi.org/10.5430/ijelt.v6n1p27

\begin{abstract}
In the face of globalization, information communication technologies (ICTs) play a paramount role in the teaching and learning of foreign languages. This action-research was conducted with a group of sophomore students enrolled in the course Composition at Universidad Nacional, Coto Campus. The study required the administration of two surveys prior to and after the implementation of Google Classroom (GC) as an educational platform to assist students during their learning process of the course. The research was aimed at revealing the students' use ICTs to practice their writing skill outside the classroom and analyzing the impact of GC in the development of the students writing skill out of the school environment. The findings exposed that the use of this platform brings about benefits that allow students and teachers to ease the teaching and learning of writing. Students also expressed that they practice their writing mainly for both academic and non-academic purposes in an engaging attractive space; lastly, students and researchers pointed out that the experience using $\mathrm{GC}$ was more satisfactory than other platforms.
\end{abstract}

Keywords: ICTs, writing, educational platform, Google Classroom

\section{Introduction}

"Teachers will not be replaced by technology, but teachers who do not use technology will be replaced by those who do." This thought-provoking statement made by Krishna (2015) definitely shakes the world upside down for those instructors who do not dare to explore the benefits of technology and prefer to stick to traditional teaching methods. The reasons for not using technological tools may vary, but probably the most well-known are the ones heard in the halls during the coffee breaks: "I'm too old to learn;" "Technology and I do not get along well;" "I have never been trained to do that;" and the like. Such reasons seem valid; however, today teachers cannot deny the need to incorporate new technologies in the classroom setting. According to Umek, Keržič, Aristovnik, and Tomaževič (2015), the use of e-learning techniques in higher education is becoming more frequent than ever. Even in some institutions, e-learning has completely replaced the traditional teaching methods, while in others it supplements classical courses (p. 1495). In addition to this, Aristovinik (2014) highlighted that technological advances have revolutionized teaching and learning processes. Fry (2001), for instance, noted that the emergence of new technologies, the rapid expiration of knowledge and training, the necessity of just-in-time information delivery, and the need for more cost-effective teaching methods have transformed teaching and learning practices to new precedents (p. 233).

Scholars have concurred on the fact that online learning platforms may be useful to teach and learn inside and outside the classroom. As Jiménez and Jiménez (2015) expressed, the literature has acknowledged that the virtual learning communities might improve the students' academic performance, stimulate collaborative learning via peer interaction, and exert responsibility on instructors to contribute with their students' learning (p. 38). In addition to these benefits, Wallace (2014) pointed out that social networking and social media platforms along with effective classroom models can work hand in hand to help raise quality standards, professionalize instructors, and motivate students (p. 294). Yet, there is still another significant positive contribution of these web-based tools when dealing with foreign language learning and teaching: the formation of autonomous learners able to solve tasks on their own with no need of commuting to receive direct instruction (Zúñiga, 2015, p. 470). All these tools under the concepts of ICTs and e- learning seem to be an ultimate solution in the learning of foreign languages because they enable 
students to communicate, edit, annotate, arrange, and create texts quickly and flexibly. Despite all these remarks, it is still arguable whether the extent to which these tools actually meet the students' expectations regarding the automatization and internalization of a foreign language when using it in developing the writing skill. Thus, this makes necessary to carry out a study that can give researchers more insight regarding the students' perception when using ICTs in developing skills for writing.

We conducted the next study with a group of English teaching sophomores taking the course Composition at Universidad Nacional (UNA), Coto Campus. Prior to this study, through an informal focus group, researcher 1 asked these students which online learning platforms they had used and how their level of satisfaction was with respect to these tools. In the former answer, they indicated that the only platform used at this point of the major was UNA-Aula Virtual, which is a web-site designed for the UNA by Moodle. In the latter response, their impressions were mostly negative due to several reasons: slow and deficient platform performance, unattractive features of UNA-Aula Virtual, and lack of familiarity with the use of web-based learning tools. In an informal conversation between researcher 1 and 2 about the results, we found that these concerns coincided by large with the findings of a research presented by researcher 2 at the V Congress of Modern Languages at Universidad de Costa Rica in 2016 (Soto \& Méndez, 2016).

Moved by a sense of cooperation and curiosity about modern pedagogical practices, both researchers embarked in developing an action research that could show that students can have more satisfactory perceptions regarding online learning platforms as long as these tools are chosen and used appropriately for the objectives of an English as Foreign Language (EFL) course. The opportunity to demonstrate this hypothesis was by developing a pedagogical proposal through the platform GC in a writing course. At this point, it is relevant to consider that students taking this course previously have indicated that writing is the most difficult linguistic skill to attain (Jiménez \& Brand, 2013), and that it was the researcher-professor's first experience teaching the said course. As a result, using the selected platform for the aforementioned course was convenient to explore solutions to surmount the problems faced with the learning of writing and to answer the next research questions:

1. How do students use ICTs outside the classroom to practice their writing skill?

2. What was the impact of GC in the development of the students writing skill outside the classroom throughout the course?

\section{Literature Review}

In the next section, we endeavor in the review of some studies related to the topic under scrutiny. The said studies shed light on the use ICTs in higher education and in EFL context. Likewise, we reviewed the Case of ICTs in the teaching of the writing skill and the use of GC in English Language Learning (ELL).

\subsection{ICTs in Higher Education}

Worldwide the use of technology in education serves several purposes. Among them, from a pedagogical perspective, experts highlight that it helps improve efficiency and efficacy in the classroom (UNESCO, 2016, p. 54). Also, it can be a tool to promote social mobility and inclusion in the sense that if teachers use it pertinently, they can develop the necessary skills that students will need to cope with the fast-changing demands of a globalized society (pp. 10-11). It is expected that technology can persuade educators to transcend and revolutionize the conventional methods used to teach in the last 30 years. Notwithstanding, such expectations have not been reached yet. The reasons are many, but the ones that concern scholars are the inability of professors to use this tool to boost students' autonomy and augment their academic performance (Ghavifekr, Kunjappan, Ramasamy, \& Anthony, 2016, pp 43-44). It seems that when teachers are in front of technological tools, the equipment becomes extremely complex and expensive for them to use. Given this reality, in the last decade, the integration of ICTs in higher education has been a constant priority by many governments and officials in different nations.

These efforts have allowed universities to offer better technological tools and resources to students. Curricula have also been updated, as now these technological tools are embedded. As a matter of fact, changes with respect to curriculum and course design, course delivery, and planning have emerged as part of the curricular development (UNESCO, 2015, p. 5). In 2015, ministers of education, high-level government officials, representatives of civil society organizations, teachers' organizations, United Nations (UN) agencies, development partners, members of the academia, and the private sector gathered at the International Conference on Information and Communication Technology in Qingdao, China. They all agreed to acknowledge the need to provide equitable access and use of ICTs in every country. Furthermore, they endorsed the creation of policies to unlock ICTs for quality and relevance of learning and their integration into teaching and learning as foundational tools to succeed in society today (UNESCO, 


\section{5, pp. 3-4).}

In Latin America, the results of the implementation of these policies have displayed positive results in countries such as Mexico and Colombia. For instance, in the university of Guadalajara, Lopez de la Madrid (2007) highlighted that ICTs implemented in the medical Syllabus of Surgeons and Obstetricians of the Southern University Center (CUSUR) have shown that more and more students search for more updated information in databases. Also, students are using the Internet as a useful tool for doing research, and they can currently work now in a more collaborative way by using forums, blogs, and chats (pp. 78-79). In the Colombian setting, the incorporation of ICTs in the educational field has allowed teachers to find innovative uses for these tools. To illustrate this, it is common for professors to use the Internet to search for information, implement software for administrative purposes, and utilize apps to prepare didactic material (Castañeda, Pimienta, \& Jaraillo, 2008, pp. 3-4). On the other hand, the same study showed that for students, ICTs were especially convenient for the presentation of information in the classroom, the search for information as a classroom activity, and the elaboration of digital products outside and inside of it (p. 3).

In brief, the cases mentioned illustrate the benefits of technology in superior education; such as apps and software that ease teachers' and students' work and boost the teaching and learning process. On the other hand, we elaborated on the international policies implemented with the purpose of training students with the necessary skills to succeed in the job market. On this account, it becomes paramount to analyze the use of ICTs in the context where the present study takes place.

\subsection{ICTs in EFL Contexts: The Case of Costa Rica}

Those higher education institutions in which the professors have embraced the use of ICTs in the teaching of English have reported positive outcomes. An illustration of this is put into perspective through a study conducted by Chaves, Chaves, and Rojas in 2015. It was aimed at identifying and analyzing the use of ICTs and pedagogical mediation utilized by the School of Literature and Language Sciences (SLLS) English Department for class enrichment purposes. The methodology was grounded on a survey applied to 25 academics imparting EFL courses. They answered a series of questions geared towards the improvement of the Bachelor's in English Teaching at SLLS through the use of ICTs in the classroom. Chaves et al. made clear that, to ensure high standards of quality in the program, the UNA has motivated its instructors to mediate activities and significant learning experiences by empowering them in the use of ICTs. Needless to say, they have been trained regarding the use of e-learning tools as means to promote learning, share experiences, rebuild knowledge, and reinforce the macro and micro-linguistic skills (p. 161).

The findings of the said research pointed out that thanks to this empowerment, both traditional and modern technological devices have converged in the classroom. Additionally, the authors remarked that certain e-learning spaces-- such as the email, virtual forums, educational platforms, Skype, wikis, Prezi, Youtube, Voki, Voicethread, online-mapping applications, blogs, and social networks-- have gained entry into the mediation of the English Department professors through an array of activities like recordings of dialogues and descriptions, pronunciation and vocabulary exercises, compositions, infographics, and other tasks that simplify students' learning and assist them in the development of their linguistic functions (p. 169). In the same vein, the informants reported that they were highly satisfied with the use of technologies, as these means approach students to native speakers of English, facilitate students' independent study through tutorials, provide instructors with visual aids and materials for pronunciation and listening comprehension tasks, and ease communication between professors and students. The academics also highlighted that the resources found on the web are innovative, dynamic, free, user-friendly, efficient, and expedite. For the professors surveyed, the importance of ICTs lies in that they feel updated upon using the technological resources, in that students' special needs are fulfilled in a full-fledged way, in that it is easier to obtain the materials available, and in that technology exposes students to more linguistic input and research sources (p. 172).

It is evident that professors in EFL contexts are becoming more and more inclined to incorporating ICTs in their lessons. Even so, at this point, we need to mention that the shortage of studies related to the teaching of writing in the EFL class reveals that it is a topic covertly explored in the Costa Rican context and thus requires more attention.

\subsection{The Case of ICTs in the Teaching of the Writing Skill}

One of the few studies that demonstrates how technology is implemented to teach writing in the Costa Rican EFL context was conducted by Quesada (2006). Such research revealed the extent to which Cyberl@b, an online interactive platform to assist EFL teachers and learners of III Cycle in the Ministry of Public Education (MEP) through an array of online exercises, can be beneficial to have students practice writing along the other linguistic skills in an engaging and autonomous way (Quesada, 2006, p. 1-25). 
Notwithstanding the above, studies conducted in other contexts, such as the one by Ziad (2016), shed light on how learning platforms similar to GC have been employed to teach writing in the past. Ziad's research took place in the Hassan II University, Moroto. It was aimed at empirically investigating semester-two students' attitude towards Moodle by explaining the extent to which students accept Moodle-hosted activities and assignments in a composition course and to which Moodle increases students' engagement with writing activities and assignments. To achieve this aim, the researcher used three data collection tools like a Moodle-generated survey, a focus group, and Moodle activities reports. The study indicated that Moodle as a learning platform was useful to develop collaborative writing activities, keep students motivated while practicing and learning out of class, and provide and receive feedback. Additionally, the participants of Ziad's study acceptance towards the tool was high inasmuch as students agreed that, aside from having difficulties with enrollment, the tool performed better than other platforms. Nevertheless, the students' perceptions varied because some rendered the said learning tool unhelpful to improve writing as long as the instructor and the onsite part of the course did not meet the requirements expected. Others attributed their progress to a combination of factors, including Moodle-based activities, while other students related their improvement directly to the platform used (pp. 314-330).

Following the previous study, it is imperative to review how GC has been used in EFL contexts to teach writing. Unfortunately, no literature was found is this regard, yet we believe it is important to make reference to studies that provide the reader with nuances on how GC has been utilized in English Language Learning (ELL). With this being said, our study will work to solve the deficiencies in the literature and thus contribute to our field of study.

\subsection{The Use of GC in ELL}

GC is an online e-learning platform released in 2014 that is already being used by many ELT professionals worldwide. Even though nothing did we find regarding studies that measure the effectiveness of this tool to assist EFL learners in the learning of their writing skill, Kasula (2016) made an invitation to reflect upon whether or not ELL is ready for this tool grounded on his experience with it, the action-research he has conducted, and a series of small-scale interviews with his colleagues. He sustained that GC can better allow teachers "[...] to display class objectives, activities, and assignments in an orderly, focused, productive and transparent manner for students, teachers, and administrators" (p.11). Moreover, GC is connected to Google Drive, enabling students to create and use documents in an online word processor, spreadsheets, and presentation programs in individual, collaborative, and group-based activities. Despite its usefulness, he recommends teachers to get self-trained and provide students with the opportunity to become accustomed to the tool to tackle the difficulties that arise more effectively. For example, Kasula remarked that its interactive nature through the Web 2.0 is affected when posts become cluttered with comments that hinder discussions in forum activities and when the overuse of posts makes the platform look disorganized. At last, the author reflected upon the pending issues when using the tool in ELL and encouraged teachers to employ this platform granted that Google Inc's adaptive tendencies are likely to make the tool even more appealing in the near future (pp. 11-12).

\section{Methodology}

This section will refer to methodological aspects of the research like the type of research, background of the study, and data analysis, which will allow to broaden the perspective on the procedures, characteristics, and principles followed to systematize the experience.

\subsection{Type of Research}

The study itself is an action research because it has the following characteristics. According to Rumbel and Mills (2016), first, it is necessary to mention that the research was conducted grounded on the experience in the classroom (p. 476). Second, we looked critically at our own teaching so that it could be enhanced by increasing both its effectiveness and quality (p. 476). Then, we as a team of EFL professors, following Rumbel and Mills (2016), have been autonomous to determine the nature of the investigation and are committed to continued professional development and school improvement by reflecting systematically on our practices. Our intent was to seek solutions to problems related to students' learning in the school context; thus, we constantly posed questions, gathered data, reflected, and decided on a course of action to solve an educational problem (p. 479). We concluded that one way to solve the issue encountered inside the classroom was by providing a remedial plan to work outside the classroom. This action plan, which will be later described, is action oriented, and its aim is to understand and improve practice (p. 489). 


\subsection{Background of the Study}

For this study, we considered to work with a group of 20 sophomore EFL students enrolled in a writing course called Composition, part of the Bachelor's in English Teaching at UNA, Coto Campus. At the start of this course, the learners had already taken two Integrated Skills courses in which the basic nuances of writing were taught. Considering the importance of technologies in the field of ELL, the professor of the course, who is also one of the researchers of this study, decided upon implementing GC as a way to interact with his students, upload information studied and additional practices, and assign take-home evaluations. With respect to the latter aspect, the course entailed as part of its summative assessment the students' written participation in the next four tasks on the platform selected.

1. The first was a question in which the students were provided with a cartoon of a female student sleeping in at the beginning of the semester but staying up late at the end of the course. The students had to engage in a forum to discuss what they planned to do to avoid the situation portrayed in the cartoon. The activity was aimed at assessing how the students used dependent and independent clauses in their writing.

2. The second evaluation was a cine-forum in which the students responded through written posts to the drama film Freedom Writers by Richard LaGravenese. The purpose of the task was to motivate the students about the importance of writing for their professional lives and assess their writing in general, stressing on the use of mechanics.

3. The third task consisted of an exercise in which the students were given three paragraphs without a topic sentence. The purpose of the activity was to create such topic sentences as a way to review the topic.

4. In regard to the fourth task, the students were requested to write their first academic paragraph of the course, taking into account aspects, such as the topic sentence, supporting details, the concluding idea, grammar, and mechanics.

As a result of the previous tasks and the practices and didactic material uploaded on the platform, the students were expected to manage their learning in an autonomous and guided way that rendered writing as a product and a process in and out of the classroom environment. The different activities proposed as well as the other uses given to the platform constitute an action plan meant to be assessed and analyzed in the second research question of this study. At this point, it is pertinent to mention that it is not part of the scope of this study to measure the effectiveness of the action plan in the improvement of writing but rather to provide insights into what the students have to say about it and the reflections that researcher 1 as the professor of the course yielded after implementing this tool.

\subsection{Data Analysis}

Two instruments were administered to conduct this study through Google Forms. Survey for Students \#1 had the purpose to collect information about EFL sophomore college students' writing habits outside the classroom and how they, as language learners, practice this skill through ICTs. A total of 10 students completed the survey. This was composed of eight close-ended questions and two open-ended questions at the end of the questionnaire. This instrument was administered at the onset of the study to answer questions $\# 1$ and $\# 2$ created at the beginning of this paper. The survey can be accessed through the link: https://docs.google.com/forms/d/e/1FAIpQLSep3JbuAswBPBYnzWSGEWX327CAsYiYDRs0Nv71AeuM2UutGQ/ viewform? $=0 \& w=1$

Survey for Students \#2 was aimed at collecting information about the students' perceptions of GC and how this platform may have contributed to the development of their writing skill in the Composition course. The instrument was answered by 9 students and consisted of close-ended and open-ended questions which provided data that allowed answering the research questions \#2 posed at the beginning of this study. The questionnaire was answered at the end of the study and can be accessed through the link:

https://docs.google.com/forms/d/e/1FAIpQLSdAMHRtaD6aLTCVsMyFCzpxIjSM_V5ccfPG7k4EDhiwuFKxFw/vie wform?usp=sf_link

At this point, it is pertinent to mention that there were many difficulties to have all students enrolled in the course answer the instruments through Google Forms although the professor sent reminders and invitations to collaborate with the research. Additionally, the information distilled through both instruments was compared and analyzed by using detailed descriptions and graphs that permitted a later reflection of the findings obtained. 


\section{Findings and Analysis}

Next, we will answer the research questions posed at the beginning of the study. More precisely, we will elaborate on the ways in which students practice their writing skill in out-of- class contexts and the impact of GC in developing students' composition skills.

\subsection{Ways to Practice the Writing Skill outside the Classroom}

This section covers aspects such as the frequency in which this skill is practiced, the activities carried out, the hardware and applications used to generate pieces of written work, and the reasons to use ICTs to practice writing.

Initially, students were asked to mention how often they practice their writing skill outside the classroom. The results obtained display a positive panorama from the start, for they indicate that $60 \%$ of informants stick to this practice at least once a week. In this sense, it is clear that most students are willing to look for opportunities to develop learning autonomy and boost their language performance in their written production. This finding can be further supported by analyzing students' responses with respect to the activities practiced in non-classroom learning spaces, which are presented in Figure 1. Here is illustrated how student use technology to carry out writing activities that allow them to be independent learners out of the classroom.

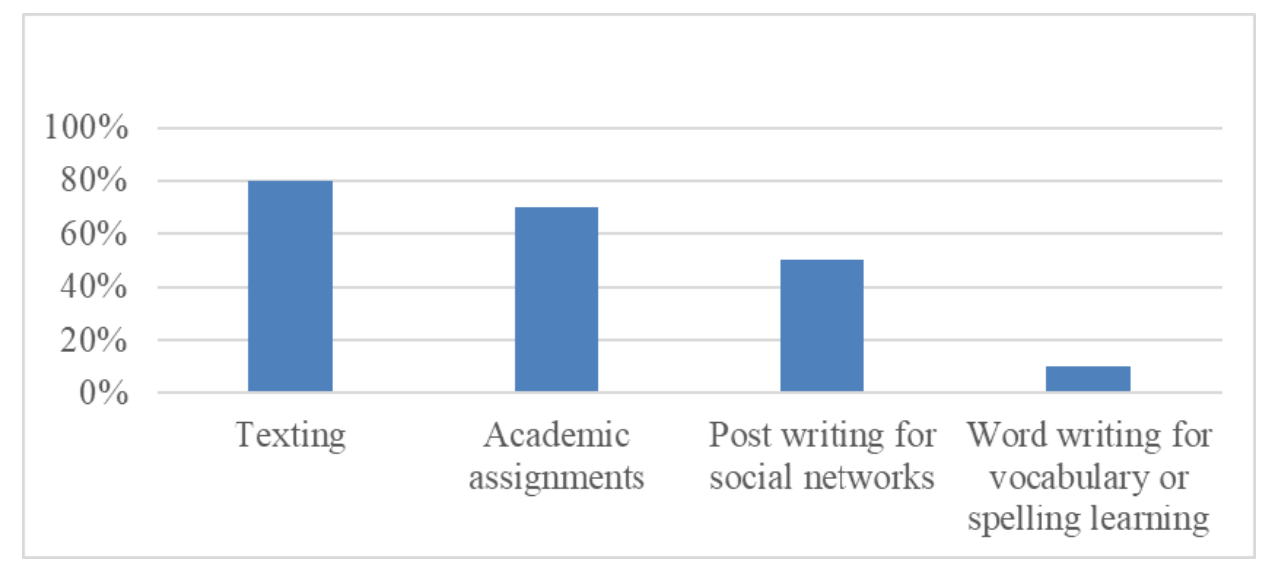

Figure 1. Writing Activities Practiced by Students outside the Classroom

The numbers presented in this graph evidence that the students surveyed opt for options that embrace the use of ICTs insofar as the percentage of learners that practice activities like texting or posting messages on social networks in the target language is higher than the one for academic assignments and word writing for vocabulary or spelling learning. The survey also revealed that these students resort to their cellphones $(100 \%)$, their computers $(90 \%)$, and their tablets $(10 \%)$ to perform the aforementioned activities. Such devices are utilized through the websites and applications noted in Figure 2.

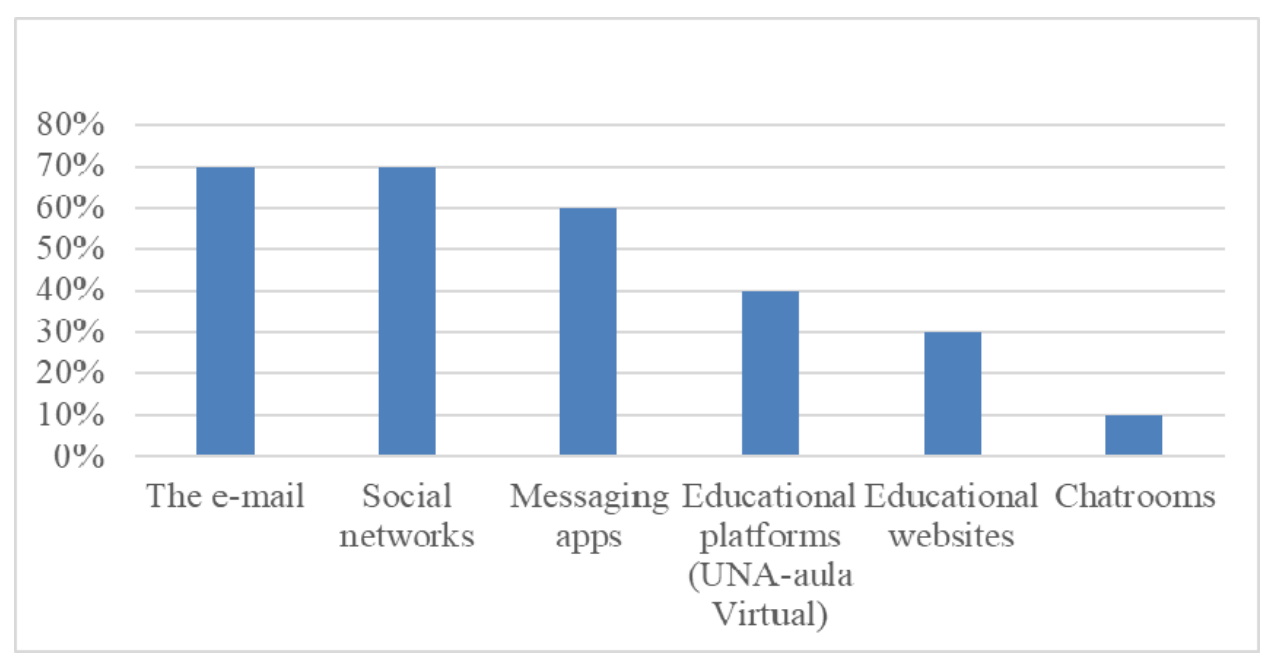

Figure 2. Websites and Applications Used to Practice Writing Outside the Classroom 
The graph displayed in Figure 2 discloses two important findings. First, the increasing popularity of more informal technological methods -social networks and messaging apps- needs to be considered for out-of-class engagement of students in their learning of the productive skill scrutinized. Second, the prominent use of more formal means, such the e-mail, educational platforms, and educational websites, is a sign of the academic concerns that students hold to improve their writing. This analysis can be intertwined with the fact that, according to Figure 1, the academic activities still seem to play an important role in the development of students' writing in an autonomous way. As a matter of fact, comparing the results of Figure 1 and Figure 2, the informants' perceptions about improving their writing for academic or professional intents seems clearer. In Figure 3, we provide informants' reasons to write in English out of class.

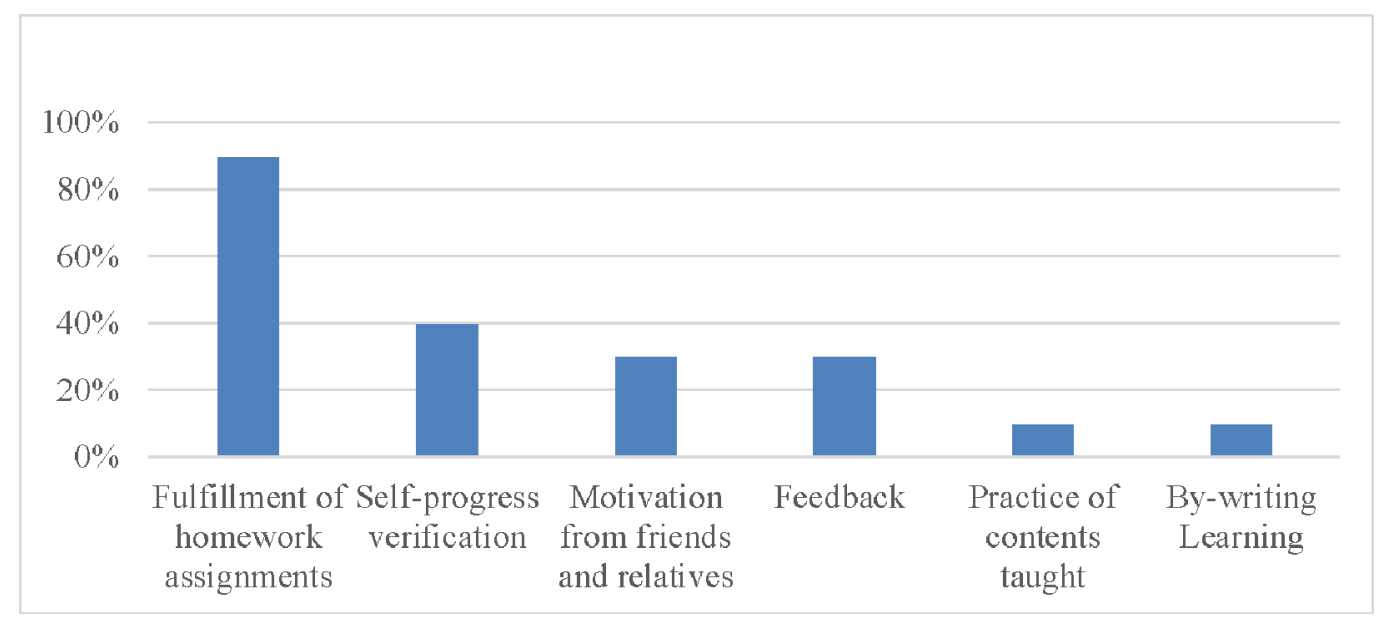

Figure 3. Reasons for Students to Write outside the Classroom

After analyzing this graph, it is conspicuous that students' motives to write out of class are mostly academic providing that aspects like fulfillment of homework assignments, self-progress verification, feedback, practice of contents taught, and by-writing learning are deemed by students to develop their writing. For this reason, it is imperative to make more useful and attractive those ICTs that students can use for academic purposes, e.g, educational platforms. In this way, students' autonomy when learning can be fostered.

\subsection{Impact of GC in the Development of Students' Writing Skill outside the Classroom}

In this section, the results from Figure 4 show that $78 \%$ of students think that GC helped them develop their writing skill. They said phrases such as the following: (1) "it is an easy way to do our homework at any moment;" (2) "[GC] helped us because we can practice more;" (3) "[it] was easy to use, and I really enjoyed the activities that we did." Other students highlighted that this tool forced them to practice more providing that they were asked to complete extra practices on a weekly basis. In general, they described the tool with adjectives like easy, practical, interactive, accessible, and useful.

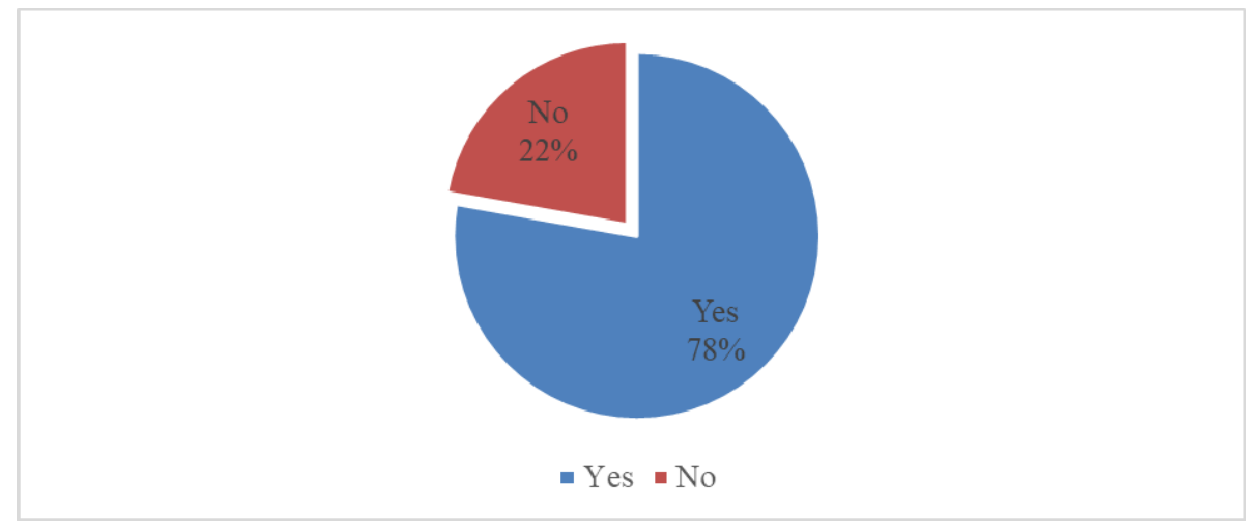

Figure 4. Extent to which GC Helped Students Develop Their Writing Skill 
Regarding the informants' expectations before using the platform, they anticipated that the tool would be useful; they also hoped that this platform could help them simplify doing their assignments and improve their writing skill by practicing with the homework assigned. Additionally, the students expressed that they wanted to learn how to write in a better way and take advantage of this tool. Moreover, other students held that GC would assist them in their learning of vocabulary. After using the platform some of these desirable wants were fulfilled; for instance, the results from Survey 2 displayed that all students enjoyed participating in the GC activities proposed by the instructor, which were described previously in the methodology section. Furthermore, others pointed out that GC was essential to practice more and make progress in their writing. One student in particular mentioned that such tool helped him/her to work on his/her own and by doing this the student gained confidence to produce without other people's help.

Based on the previous data, it is evident that this platform influenced students' behavior directly considering the time invested in developing their writing skill. When comparing Survey 1 and 2, it is perceived that students in an unconscious way linked certain technological tools to entertainment such as social networks, and other platforms were linked to academic purposes such as GC. Thus, they may prefer to spend more time on social networks instead of using GC to practice their writing skill. Then, regarding the reasons why they write outside the class, it seems that the tool GC plays a major role in motivating students to practice their writing instead of using their time on non-educational technological tools or social networks. It was a thought-provoking datum to see that students do not write outside the classroom as a hobby, instead they write for communicative purposes mainly. The extent to which an innovative tool affects students' writing skill development in a positive manner will depend heavily upon the amount of time devoted to using the platform in their free time.

\section{Conclusions and Final Reflections}

Since the beginning, both of us, researcher 1 and 2, engaged in a critical dialogue about our experiences using technological platforms in our courses. At the start, we agreed that some educational platforms can be unattractive and unfamiliar for students despite the fact that the research conducted by researcher 2 (2016) showed that e-learning platforms improved students' participation.

However, the findings of the present action-research suppose a broader space for reflection. First, the activities and ICTs used by students to practice the language outside the classroom are clear indicators that they look forward to being more independent learners. This can be linked to the contributions underpinned by Quesada (2006), Zúñiga (2015) and Chaves et. al (2015) who acknowledged the usefulness of virtual platforms to help students learn in an autonomous way. This was not the exception when implementing GC to assist students' in the enhancement of their writing skill. Through the teaching experience of researcher 1 in the writing course, though, it was noticed that when teaching certain topics, students constantly asked to upload additional practice in the platform. This leads us to ask ourselves: to what extent is this educational platform helpful to foster learning autonomy if the teacher has to provide the means to learn in this way? This question seems to be unanswered although we recognize that the platform contributes in the development of independence when learning, for it makes students to work on their own through the activities assigned and the extra practice given.

Another significant result obtained from the study is related to students' expectations before using GC. As a matter of fact, the platform fulfilled their predictions because they expected the tool to be useful; they also hoped that GC would help them simplify doing their assignments and polish their writing skill. This coincides with Ziad's (2016) conclusion on Moodle: a learning platform useful to develop writing activities that can keep students motivated while practicing and learning out of class. In this scenario, it is pertinent to clarify that GC and Moodle platforms are not the same; there are slight differences to consider before using them; notwithstanding, such technological tools can satisfy students' needs and expectations if they are used to innovate in a course. That is what researcher 1 aimed at doing with his action plan in the platform, and the results are highly satisfactory in accordance with the results of the surveys applied and our reflections as researchers, as the platform also met our expectations in helping students practice the writing skill in an engaging, autonomous, and interactive manner.

\section{References}

Aristovnik, Aleksander. (2014). Development of the Information Society and Its Impact on the Education Sector in the EU: Efficiency at the Regional (NUTS 2) Level. The Turkish Online Journal of Educational Technology, 13(2), 54-60.

Castañeda, Claudia., Pimienta, Martha., \& Jaramillo, P. (2008). Usos de TIC en la Educación Superior. IX Congreso 
Iberoamericano de Informática Educativa (pp. 1-6). Caracas: RIBIE.

Chaves, Olga., Chaves, Lindsay., \& Rojas, Didier. (2015). La realidad del uso de las TIC y su mediación pedagógica para enriquecer las clases de inglés. Revista Ensayos Pedagógicos, 10(1), 150-183.

Fry, Kate. (2001). E-learning markets and providers: some issues and prospects. Education + Training, 43(4/5), 233-239. https://doi.org/10.1108/EUM0000000005484

Ghavifekr, Simin., Kunjappan, Thanusha., Ramasamy, Logeswary., \& Anthony, Annreetha. (2016). Teaching and Learning with ICT Tools: Issues and Challenges from Teachers' Perceptions. Malaysian Online Journal of Educational Technology, 4(2), 38-57.

Jiménez, Karla., \& Jiménez, Vanessa. (2015). Comunidades virtuales de aprendizaje: Una herramienta para fomentar la inclusión en la Enseñanza del Inglés desde la contextualización curricular. Revista Ensayos Pedagógicos, $10(1), 33-54$.

Jiménez, Yalile., \& Brand, Kevin. (2013). Assisting EFL learners in the development of writing skills through cognitive and compensatory learning strategies. Paper presented at IV Congress of Applied Linguistics (CILAP).

Kasula, Alex. (2015). Is Google Classroom ready for ELL? The Word, 24(2), 11-13.

Krishna, Hari. (2015, March 12). Daily Edventure. Retrieved from http://dailyedventures.com/index.php/2015/03/12/hari-krishna-arya/

López de la Madrid, María. (2007). Uso de las TIC en la Educación Superior de México. Un estudio de Caso. Apertura, 7, 63-79.

Quesada, Allen. (2006). Cyberl@b: A platform for learning English in Costa Rican public high schools. Revista Actualidades Educativas en Educación, 6(3), 1-25. https://doi.org/10.15517/AIE.V613.9220

Rumbel, Lorraine., \& Mills, Geoffrey. (2016). Educational Research Competencies for Analysis and Application. United Kingdom: Pearson Education.

Soto, Federico., \& Méndez, Juan. (2016). Using technology-based instruction in general linguistics: How does it change classroom dynamics? Paper presented at the V Congress of Modern Languages.

Umek, Lan., Keržič, Damijana., Aristovnik, Aleksander., \& Tomaževič, Nina. (2015). Analysis of selected aspects of students' performance and satisfaction in a Moodle-based e- learning system environment. Eurasia Journal of Mathematics, Science \& Technology Education, 11(6), 1495-1505. https://doi.org/10.12973/eurasia.2015.1408a

UNESCO. (2015). QINGDAO DECLARATION. Seize digital opportunities, lead education transformation QINGDAO DECLARATION (pp. 2-8). Qingdao: UNESCO.

UNESCO. (2016). ICT Standards and Competencies from the Pedagogical Dimension: A perspective from levels of ICT adoption in teachers' education practice. Cali: Universidad Javeriana.

Wallace, Albin. (2014). Social learning platforms and the flipped classroom. International Journal of Information and Education Technology, 4(4), 293-296. https://doi.org/10.7763/IJIET.2014.V4.416

Ziad, Hicham. (2016). Technology-mediated ELT writing: Acceptance and engagement in an online Moodle course. Contemporary Educational Technology, 7(4), 314-330.

Zúñiga, Lesly. (2015). EFL Professors' perceptions and intentions towards the integration of the tools in UNA Virtual Program at UNA Brunca Campus. Memoria: II Congreso de Lingüistica Aplicada Effective Teaching Practices: The Key to Maximixing Learning, 458-475. 